\title{
Consequences of Interdialytic Weight Gain Among Hemodialysis Patients
}

Mojgan Jalalzadeh ${ }^{1}$, Seyednouraddin Mousavinasab ${ }^{2}$, Camila Villavicencio ${ }^{3}$, Muhammad Aameish ${ }^{1}$, Shobhana Chaudhari ${ }^{4}$, Donald Baumstein ${ }^{1}$

1. Internal Medicine/Nephrology, Metropolitan Hospital Center, New York Medical College, New York, USA 2. Advanced Statistical Modeling, Mazandaran University of Medical Sciences, Mazandaran, IRN 3. Internal Medicine, Metropolitan Hospital Center, New York Medical College, New York, USA 4. Internal Medicine/Geriatrics, Metropolitan Hospital Center, New York Medical College, New York, USA

Corresponding author: Mojgan Jalalzadeh, jmojgan1341@gmail.com

\section{Abstract}

Background

Interdialytic weight gain (IDWG) is a marker of higher pre-dialysis blood pressure, nutrition, and survival in hemodialysis (HD) patients. However, this relationship is incompletely characterized. In this study, we seek to define the association of IDWG/dry weight x100 (IDWG\%) on blood pressure (BP), and the nutritional status of an HD population.

Material and Methods

This study was performed on $300 \mathrm{HD}$ patients. The data was collected over four weeks, including total IDWG, IDWG\%, and blood pressure. Normalized protein nitrogen appearance (nPNA), and serum albumin were used as markers of nutritional status. Participants were divided into three groups according to the mean of the IDWG\% between two sessions of $\mathrm{HD}$ (group $\mathrm{A}<3 \%$, group $\mathrm{B}=3 \%-3.9 \%$, and group $\mathrm{C} \geqslant 4 \%$ ); they were then compared on various aspects. Student t-test, analysis of variance (ANOVA), and linear regression analysis were used as statistical tools.

Results

The mean ( \pm standard deviation (SD)) age was $61.7 \pm 14.2$ years with $57.7 \%$ of the patients being male and $42.3 \%$ being female. The mean IDWG\% for the whole studied population was $3.72 \% \pm 1.73 \%$. Between these three groups, a higher IDWG\% was associated with younger males $(p=0.032)$, lower dry weight $(p=0.009)$, and longer duration on HD therapy $(p=0.009)$. IDWG\% was directly associated with lower pre-dialysis serum sodium $(\mathrm{p}=0.04)$, higher pre-dialysis serum creatinine $(\mathrm{P}=0.002)$, and lower body mass index $(\mathrm{BMI})(\mathrm{p}=$ 0.003). Between these three groups, interdialytic variations in weight gain were not associated with increased BP. There was no significant difference between the three groups in terms of nPNA and serum albumin.

Review began 04/12/2021 Review ended 04/19/2021 Published 05/13/2021

๑) Copyright 2021

Jalalzadeh et al. This is an open access article distributed under the terms of the Creative Commons Attribution License CC-BY 4.0, which permits unrestricted use, distribution, and reproduction in any medium, provided the original author and source are credited.

\section{Conclusions}

The most important associations of IDWG\% are age, weight, pre-dialysis sodium, serum creatinine, and duration of dialysis (months). There was no association between IDWG\% and increased systolic BP. IDWG\% had no association with nutritional status.

Categories: Internal Medicine, Nephrology

Keywords: interdialytic weight gain, hemodialysis, high blood pressure, nutritional status

\section{Introduction}

At all stages of chronic kidney disease (CKD), sodium and water overload may cause plasma volume expansion, left ventricular (LV) dilatation, and LV hypertrophy. This is particularly seen in dialysis patients [1-2]. Hypertension (HTN) and malnutrition are common problems among patients undergoing chronic hemodialysis (HD). HTN is often uncontrollable in HD patients. Causes of HTN are multifactorial, but there is a direct relationship between volume and HTN.

Interdialytic weight gain (IDWG) is used as a parameter for fluid and salt intake between the two sessions of HD. IDWG was measured as the pre-dialysis weight prior to HD treatment, minus the prior session postdialysis weight. It influences blood pressure and survival of HD patients [3-7]. However, the extent to which interdialytic volume gains affect BP in HD patients is less clear and remains controversial [3, 8-9]. Fluid restriction, longer sessions of dialysis, frequent dialysis sessions, and correction of sodium dialysate 
concentrations have been suggested to reduce IDWG [10]. Dietary salt restriction is necessary for the dialysis population in the management of HTN and IDWG [11].

At the same time, IDWG is a marker of nutrition in HD patients [3]. Malnutrition among HD patients can lead to an increased morbidity and mortality rate [12-13]. Daily protein intake, estimated by normalized protein nitrogen appearance (nPNA), is calculated from urinary nitrogen output and non-urea nitrogen losses. Dialysis should be started when the nPNA falls below $0.8 \mathrm{~g} / \mathrm{kg}$ per day to prevent deterioration of nutritional status and leads to a better clinical outcome. Also, when nPNA in HD maintenance patients is low, it usually indicates a low dietary intake [14]. Reasons for malnutrition in dialysis patients include decreased appetite and food intake, chronic inflammation, and decreased physical activity [15]. Several studies have shown that higher IDWG is associated with improvement of nutritional status [3, 5-6].

Herein, we sought to identify the influence of IDWG\% and not IDWG, as done in many other studies on BP and nutritional status in HD patients. IDWG\% is IDWG/dry weight $x 100$, and dry weight (DW) is the patient's weight without the excess fluid that builds up between dialysis treatments.

\section{Materials And Methods}

This prospective study was conducted on $300 \mathrm{HD}$ patients at four HD centers in the Provinces of Zanjan and Tehran in Iran for one month. The study was approved by the Research Ethics Committee of the Zanjan University of Medical Science (approval \#08/90-327-02). All patients signed a consent form prior to data collection.

The association of IDWG\% (as a percentage of IDWG/dry body weight) on BP and nutritional status was investigated. Inclusion criteria included patients aged $\geqslant 16$ years with more than six months on maintenance HD three times weekly. Incomplete data at analysis time were considered as exclusion criteria. Participants were divided into three groups according to IDWG\%: Group A $<3 \%$, Group B $=3 \%-3.9 \%$, and Group C $>4 \%$ in between two sessions of dialysis. All examination and laboratory values were collected when patients reached their dry weight. Dry weight was defined to achieve an edema-free state and no orthostatic hypotension at the end of the HD session. IDWG was calculated as the pre-dialysis weight prior to HD treatment, minus the prior session post-dialysis weight. Blood pressure was measured manually by the staff of the dialysis unit shortly before the HD session, and the weight was measured before and after HD treatment. IDWG and blood pressure were averaged for pre-dialysis measurement of three hemodialysis sessions per week for four weeks and were used for statistical analysis. The serum albumin level and nPNA, which reflect the daily protein intake, were used to evaluate nutritional status. The nPNA was calculated with the equation of Bergström, nPNA $=0.45 \mathrm{Kt} / \mathrm{V}_{\text {urea }}+0.38$ (urea clearance normalized to total body water). Individuals who prescribed antihypertensive medications and with blood pressure more than 140/85 were considered to have hypertension. Serum pre-dialysis cholesterol, triglycerides, fasting glucose, hemoglobin (Hgb), albumin (Alb), calcium, phosphorus, and C-reactive protein (CRP) were measured. To evaluate the efficacy of dialysis, $\mathrm{Kt} / \mathrm{V}$ was calculated. Dialysis duration (defined as a month of dialysis therapy), age, and gender were extracted from patients' records and saved. The HD protocol for all patients was four hours of HD using hemophane membranes, with a blood flow rate of $300-350 \mathrm{~mL} / \mathrm{min}$ and dialysate flow rate of $500-700 \mathrm{~mL} / \mathrm{min}$, bicarbonate bath, on a thrice-weekly schedule. All our patients were dialyzed with a sodium dialysis concentration of $139 \mathrm{mmol} / \mathrm{L}$.

\section{Statistical analysis}

Data were reported as mean \pm standard deviation (SD) for continuous variables with normal distributions and numbers (percent) for categorical data. Demographic characteristics, laboratory data, and blood pressures were categorized into three groups of IDWG\%. Differences between these groups were analyzed with analysis of variance (ANOVA) followed by Tukey's honestly significant difference (HSD) post-hoc test or the Kruskal Wallis nonparametric test as appropriate. For categorical data, the Pearson Chi-squared test was used. IDWG or IDWG\% was entered as a response variable. Spearman correlation and multivariate linear regression analysis were performed to identify associations between IDWG or IDWG\% with systolic and diastolic BP and other variables, including various nutritional parameters. The following possible explanatory variables were entered into the model: age, gender, weight, height, Kt/V, serum albumin, and pre-dialysis plasma sodium concentration. Also, bivariate analyses were used to independently identify variables associated with systolic BP. Then, significant factors in bivariate analysis with a P-value less than 0.5 were entered into a multivariable model to describe the relationship between BP with IDWG\% and each clinical and demographic characteristic. Statistical analyzes were performed with the IBM Statistical Package for Social Sciences (SPSS), version 20 (IBM SPSS Statistics for Windows, Armonk, NY). Two-tailed Pvalues $<0.05$ were considered statistically significant.

\section{Results}

Three hundred HD patients were enrolled in this study, including 173 males (58\%) and 127 females (42.3\%) with a mean age of $61.77 \pm 14.2$. High blood pressure was detected in $83.7 \%$ ( 251 patients) and diabetes mellitus (DM) in 52\% (156 patients). The mean BMI, weight gain, and IDWG\% were $24.07 \pm 4.13,2.32 \mathrm{~kg} \pm 1.1$, and $3.72 \% \pm 1.73$, respectively. Table 1 shows the demographic data of the patients. 


\section{Cureus}

\begin{tabular}{|c|c|}
\hline Variable & Value \\
\hline Number & 300 \\
\hline Sex (Male/Female\%) & $173(58 \%), 127$ (42.3\%) \\
\hline \multicolumn{2}{|l|}{ Age $($ mean $\pm S D)$ years } \\
\hline Male & $61.27 \pm 14.7$ \\
\hline Female & $62.45 \pm 13.5$ \\
\hline Height (cm) & $166.1 \pm 8.7$ \\
\hline Diabetes mellitus & $156(52 \%)$ \\
\hline Cardiovascular events & $63(21 \%)$ \\
\hline Cerebrovascular accident & $72(24 \%)$ \\
\hline \multicolumn{2}{|l|}{ Metabolic features } \\
\hline Hypertension & $251(83.7 \%)$ \\
\hline Systolic BP (mm Hg) & $140.9 \pm 18.2$ \\
\hline Diastolic BP (mm Hg) & $83.6 \pm 9.1$ \\
\hline Low HDL & $145(48.3 \%)$ \\
\hline Abnormal glucose metabolism & $140(46.7 \%)$ \\
\hline Elevated triglycerides & $103(34.3 \%)$ \\
\hline Abdominal obesity & $124(41.3 \%)$ \\
\hline \multicolumn{2}{|l|}{ Measurements } \\
\hline Dry weight $(\mathrm{kg})$, mean $\pm \mathrm{SD}$ & $63.8 \pm 12.5$ \\
\hline Interdialytic weight gain (IDWG) $(\mathrm{kg})$, mean \pm SD & $2.32 \pm 1.1$ \\
\hline IDWG\% (IDWG/DW, \%), mean & $3.72 \pm 1.73$ \\
\hline \multicolumn{2}{|l|}{ Serum laboratory features } \\
\hline Fasting blood sugar (mg/dL) & $121.4 \pm 61.7$ \\
\hline Cholesterol (mg/dL) & $157.7 \pm 42.1$ \\
\hline Triglyceride (mg/dL) & $149.7 \pm 90.5$ \\
\hline HDL, mg/dL & $44.8 \pm 10.6$ \\
\hline Blood urea nitrogen $(\mathrm{mg} / \mathrm{dL})$ & $76.7 \pm 46.5$ \\
\hline Creatinine $(\mathrm{mg} / \mathrm{dL})$ & $8.7 \pm 2.5$ \\
\hline Sodium (mEq/L) & $138.8 \pm 3.5$ \\
\hline Calcium (mEq/L) & $9.03 \pm 0.7$ \\
\hline Phosphorus (mEq/L) & $4.9 \pm 1.2$ \\
\hline Albumin (mg/dL) & $4.0 \pm 0.56$ \\
\hline CRP & $20(0-120)$ \\
\hline Duration of dialysis (months), median (min-max) & $48(12-192)$ \\
\hline $\mathrm{Kt} / \mathrm{V}$ & $1.21 \pm 0.25$ \\
\hline nPNA (g/kg/day) & $0.92 \pm 0.1$ \\
\hline BMI & $24.07 \pm 4.1$ \\
\hline
\end{tabular}




\section{Cureus}

TABLE 1: Demographic, Metabolic, and Laboratory Features of Patients on Hemodialysis

IDWG and blood pressure were averaged for pre-dialysis measurement of three hemodialysis sessions per week for four weeks.

BMI: body mass index; BP: blood pressure; CRP: C-reactive protein; HDL: high-density lipoprotein; IDWG: current predialysis weight (kg) - previous postdialysis weight (kg); IDWG\%: current predialysis weight $(\mathrm{kg})$ - previous postdialysis weight $(\mathrm{kg}) / \mathrm{target}$ dry weight (kg) x100; Kt/V: urea clearance normalized to total body water; nPNA: normalized protein nitrogen appearance; SD: standard deviation

Table 2 shows the clinical results and the analysis of the three groups of the patients according to the IDWG\%. Thirty-six percent were in group A (IDWG\% < 3\%), 24\% in group B (IDWG\%: $3 \%-3.9 \%$ ), and $40 \%$ in group C (IDWG\% $\geqslant 4 \%$ ). Higher systolic pre-dialysis blood pressure was detected in $78.5 \%$ of patients in group A, in $89 \%$ of patients in group-B, and in $85.0 \%$ of patients in group-C. There was no difference between three groups in terms of $\mathrm{BP}(\mathrm{P}=0.15)$, nutritional elements of $\mathrm{nPNA}$, and serum albumin $(\mathrm{p}=$ $0.41)$. IDWG\% was significantly higher in younger males $(p=0.027)$, those with lower DW $(p=0.009)$, lower BMI $(p=0.003)$ and longer duration on HD therapy $(p=0.009)$. IDWG\% was not associated with height $(P=$ $0.95)$. Patients with higher IDWG\% had lower level of pre-dialysis serum $\mathrm{Na}(\mathrm{p}=0.04)$, and higher predialysis serum creatinine $(\mathrm{p}=0.002)$. 


\section{Cureus}

\begin{tabular}{|c|c|c|c|c|}
\hline Variables & Group A IDWG\% < 3 & Group B IDWG\% (3 - 3.9) & Group C IDWG\% $\geq 4$ & P-value \\
\hline Number of patients, $\%$ & $107(35.7 \%)$ & $73(24.3 \%)$ & $120(40 \%)$ & - \\
\hline Gender (Female/Male) & $44 / 63$ & $31 / 42$ & $52 / 68$ & 0.94 \\
\hline Age $($ mean $\pm S D)$ & $63.27 \pm 14.8$ & $63.16 \pm 13.8$ & $59.58 \pm 13.7$ & 0.039 \\
\hline Male's age & $64.13 \pm 13.8$ & $62.29 \pm 15.3$ & $58.00 \pm 14.7$ & 0.027 \\
\hline Female's age & $62.05 \pm 16.8$ & $64.35 \pm 11.5$ & $61.65 \pm 12.2$ & 0.72 \\
\hline Height & $164.2 \pm 8.9$ & $164.11 \pm 7.7$ & $163.9 \pm 9.0$ & 0.95 \\
\hline Diabetes mellitus & $58(54.2 \%)$ & $43(58.9 \%)$ & $55(45.8 \%)$ & 0.18 \\
\hline Hypertension & 84 (78.5\%) & 65 (89.0\%) & $102(85.0 \%)$ & 0.15 \\
\hline \multicolumn{5}{|l|}{ Measurements } \\
\hline Dry weight, mean \pm SD & $65.6 \pm 13.1$ & $65.5 \pm 11.4$ & $61.1 \pm 12.2$ & 0.009 \\
\hline Interdialytic weight gain (IDWG) (kg), mean \pm SD & $1.34 \pm 0.6$ & $2.28 \pm 0.4$ & $3.25 \pm 0.8$ & $<0.001$ \\
\hline IDWG\%, mean & $2.01 \pm 0.8$ & $3.48 \pm 0.3$ & $5.38 \pm 1.2$ & $<0.001$ \\
\hline \multicolumn{5}{|l|}{ Outcome } \\
\hline Pre-dialysis systolic BP, mm Hg & $130(80-200)$ & $130(90-200)$ & $130(90-180)$ & 0.38 \\
\hline Pre-dialysis diastolic BP, mm Hg & $80(50-110)$ & $80(50-100)$ & $80(50-110)$ & 0.81 \\
\hline $\mathrm{nPNA}(\mathrm{g} / \mathrm{kg} /$ day) & $0.91 \pm 0.1$ & $0.93 \pm 0.08$ & $0.94 \pm 0.12$ & 0.11 \\
\hline \multicolumn{5}{|l|}{ Serum laboratory features } \\
\hline Blood urea nitrogen (mg/dL) & $63(17-242)$ & $67(19-243)$ & $62(19-259)$ & 0.43 \\
\hline Creatinine (mg/dL) & $8.01 \pm 2.4$ & $8.86 \pm 2.7$ & $9.17 \pm 2.5$ & 0.002 \\
\hline Sodium (mEq/L) & $139.5 \pm 3.5$ & $138.4 \pm 3.3$ & $138.5 \pm 3.5$ & 0.04 \\
\hline Calcium & $8.9 \pm 0.7$ & $9.15 \pm 0.6$ & $9.07 \pm 0.7$ & 0.085 \\
\hline Phosphorous & $4.8 \pm 1.1$ & $5.02 \pm 1.3$ & $4.9 \pm 1.2$ & 0.63 \\
\hline Albumin (mg/dL) & $4.0 \pm 0.7$ & $4.0 \pm 0.5$ & $4.0 \pm 0.5$ & 0.96 \\
\hline CRP & $0(0-120)$ & $20(0-120)$ & $20(0-80)$ & 0.97 \\
\hline Duration of dialysis (months), median (min-max) & $36(12-120)$ & $36(12-144)$ & $48(12-192)$ & 0.009 \\
\hline $\mathrm{Kt} / \mathrm{N}$ & $1.18 \pm 0.25$ & $1.22 \pm 0.18$ & $1.25 \pm 0.27$ & 0.11 \\
\hline BMI & $24.3 \pm 4.3$ & $24.3 \pm 3.9$ & $22.6 \pm 3.8$ & 0.003 \\
\hline
\end{tabular}

\section{TABLE 2: Clinical and Analytical Characteristics of 300 Patients According to the Three Groups of}

Percentage Interdialytic Weight Gain/Dry Weight (IDWG\%)

Results are expressed as mean \pm standard deviation (SD) or median (min-max). Statistical comparison was performed with analysis of variance (ANOVA), Kruskal Wallis, or Chi-squared tests.

IDWG = current predialysis weight $(\mathrm{kg})$ - previous postdialysis weight $(\mathrm{kg})$; IDWG\% = current predialysis weight $(\mathrm{kg})$ - previous postdialysis weight $(\mathrm{kg}) /$ target dry weight $(\mathrm{kg}) \times 100$

BMI: body mass index; BP: blood pressure; CRP: C-reactive protein; Kt/V: urea clearance normalized to total body water; nPNA: normalized protein nitrogen appearance; SD: standard deviation

Table 3 shows the correlation between IDWG\% and numerical measurements. There was a significant inverse correlation between IDWG\% with age $(r=-0.129, P=0.026)$, dry weight $(r=-0.173, P=0.003)$, waist circumference $(r=-0.128, p=0.026)$, BMI $(r=-0.180, p=0.002)$, pre-dialysis serum sodium $(r=-0.151, P=$ $0.009)$, and a positive correlation with the duration of dialysis therapy $(\mathrm{r}=0.164, \mathrm{P}=0.004)$. There was no 


\section{Cureus}

significant correlation with systolic and diastolic BP. All of the results in this analysis are consistent with the results in Table 2.

IDWG\%

$\begin{array}{lll}\text { Variables } & r^{\star} & P \\ \text { Age } & -0.129 & 0.026 \\ \text { Waist circumference } & -0.128 & 0.026 \\ \text { BMI } & -0.180 & 0.002 \\ \text { Duration of dialysis } & 0.164 & 0.004 \\ \text { Creatinine } & 0.200 & <0.001 \\ \text { Sodium } & -0.151 & 0.009 \\ \text { Alkaline phosphatase } & 0.198 & 0.001 \\ \text { Dry weight } & -0.173 & 0.003 \\ \text { Systolic BP } & -0.020 & 0.730 \\ \text { Diastolic BP } & -0.035 & 0.544\end{array}$

\section{TABLE 3: The Association of Clinical and Analytical Characteristics with IDWG\%}

*Spearman correlation

BMI: body mass index; BP: blood pressure; IDWG\%: interdialytic weight gain/dry weight x100

Table 4 shows the correlation between systolic and diastolic BP and numerical measurements. Young age was correlated with higher $\mathrm{BP}(\mathrm{r}=-0.177, \mathrm{P}=0.002)$ in the univariate analysis. However, sex, diabetes, and longer duration of dialysis were not associated with high BP. There was a significant inverse correlation between systolic BP with hemoglobin $(\mathrm{Hgb})(\mathrm{r}=-0.202, \mathrm{P}<0.001)$ and hematocrit $(\mathrm{Hct})(\mathrm{r}=-0.169, \mathrm{p}=$ $0.003)$, as well as a positive correlation with fasting blood sugar (FBS) $(r=0.152, p=0.008)$ and blood urea nitrogen $(\mathrm{BUN})(\mathrm{r}=0.127, \mathrm{p}=0.028)$. The same correlations also were found for diastolic $\mathrm{BP}$.

\begin{tabular}{|c|c|c|c|c|}
\hline \multirow[b]{2}{*}{ Variables } & \multicolumn{2}{|c|}{ Systolic BP } & \multicolumn{2}{|c|}{ Diastolic BP } \\
\hline & $r^{*}$ & $P$ & $r^{*}$ & $P$ \\
\hline Age & -0.177 & 0.002 & -0.153 & 0.008 \\
\hline FBS & 0.152 & 0.008 & 0.132 & 0.022 \\
\hline BUN & 0.127 & 0.028 & 0.179 & 0.002 \\
\hline Hemoglobin & -0.202 & $<0.001$ & -0.158 & 0.006 \\
\hline Hematocrit & -0.169 & 0.003 & -0.129 & 0.026 \\
\hline
\end{tabular}

TABLE 4: The Association of Clinical and Analytical Characteristics with Systolic BP and Diastolic BP

*Spearman correlation

BP: blood pressure; BUN: blood urea nitrogen; FBS: fasting blood sugar

Table 5 shows the variables that have a statistically significant effect on systolic BP by a stepwise regression method. In bivariate analysis, factors with a P-value $<0.5$ were entered into a multivariable model. Since the P-value of the IDWG\% was not less than 0.5 , it was not entered into a multivariable model. Increased hemoglobin and hematocrit level and age were associated with lower pre-dialysis systolic BP. In 


\section{Cureus}

multivariable analyses, greater hemoglobin remained a significant predictor of lower pre-dialysis systolic BP with a coefficient of $r^{2}=0.03$

\begin{tabular}{|c|c|c|c|c|}
\hline Variables & $\begin{array}{l}\text { Bivariate Parameter Estimates of } \\
\text { Slope }\end{array}$ & $\begin{array}{l}\text { P- } \\
\text { Value }\end{array}$ & Multivariable Parameter Estimate of Slope & P-Value \\
\hline Hemoglobin & $-1.77 \pm 0.55$ & 0.001 & $-1.76 \pm 0.55$ & 0.001 \\
\hline Age & $-0.157 \pm 0.07$ & 0.034 & & \\
\hline Hematocrit (\%) & $-0.44 \pm 0.17$ & 0.013 & & \\
\hline BUN (mg/dL) & $0.04 \pm 0.02$ & 0.075 & & \\
\hline $\mathrm{Ca}(\mathrm{mg} / \mathrm{dL})$ & $2.41 \pm 1.48$ & 0.105 & & \\
\hline Triglycerides (mg/dL) & $-0.018 \pm 0.01$ & 0.114 & & \\
\hline Potassium (mEq/L) & $1.99 \pm 1.4$ & 0.148 & & \\
\hline $\begin{array}{l}\text { Abnormality glucose }(>126 \text { vs }< \\
126)\end{array}$ & $2.79 \pm 2.1$ & 0.183 & & \\
\hline Ferritin (ng/mL) & $-0.002 \pm 0.002$ & 0.290 & & \\
\hline Height $(\mathrm{cm})$ & $0.122 \pm 0.12$ & 0.312 & & \\
\hline Phosphorous (mg/dL) & $0.79 \pm 0.86$ & 0.360 & & \\
\hline CRP (mg/L) & $0.031 \pm 0.03$ & 0.39 & & \\
\hline Sodium (mEq/L) & $0.248 \pm 0.30$ & 0.410 & & \\
\hline Cholesterol (mg/dL) & $-0.020 \pm 0.02$ & 0.427 & & \\
\hline DM (vs no DM) & $-1.66 \pm 2.14$ & 0.44 & & \\
\hline
\end{tabular}

TABLE 5: Bivariate and Multivariable Predictors of Pre-dialysis Systolic Blood Pressure in Hemodialysis Patients

Note: Values expressed as mean \pm standard error (SE). Selected multivariable regression models were done by a stepwise method.

BUN: blood urea nitrogen; Ca: calcium; CRP: C-reactive protein; DM: diabetes mellitus

\section{Discussion}

In the present study, we found higher IDWG\% was associated with younger males, lower dry weight, and longer time on HD therapy. We speculate that younger patients drink more fluid because of increased physical and social activity, leading to higher IDWG\%. Our results suggest that dietary advice, including fluid restriction, should be individualized based on age and body weight. In older patients, besides volume, multifactorial elements affect the blood pressure. Rahman et al. showed that high IDWG and younger age were independent predictors of higher BP and advancing age was associated with lower BP levels in this population [16]. We also found advancing age as a predictor of lower pre-dialysis systolic blood pressure but report that patients with the highest IDWG\% did not have higher pre-dialysis systolic BP between these three groups (Table 5). BP was the same across all groups; this result likely is because the age of our population.

Our results showed that greater IDWG and IDWG\% were not associated with better nutritional status. There was no significant difference in serum albumin, serum phosphorus (as a marker for protein intake in dialysis patients), and nPNA between the three groups. Some studies have reported that strict control of salt and fluids may affect nutritional status and lead to inadequate protein and calorie intake [17]. Ipema et al., in contrast with other studies [3, 5-6], did not find a strong association between IDWG and nutritional indicators, such as serum albumin and nPNA [18]. This study showed that there was a negative correlation between BMI and IDWG\%. Sezer et al. has shown that patients with IDWG\% > 3\% had higher BMI than those who had an IDWG\% < 3\% [9].

Hecking and colleagues described that patients with high IDWG had low pre-dialysis sodium [19], which is similar to the results of the present study. 
There was no significant association between IDWG and IDWG\% with serum BUN, calcium-phosphorus (Ca $\mathrm{x}$ P) product, CRP, ferritin, anemia, Kt/V, and metabolic syndrome in studied patients. Regression analysis showed that increased hemoglobin can predict a 3\% change in systolic blood pressure.

\section{Conclusions}

We did not find an association between IDWG\% and increased systolic BP or nutritional status. Our results showed that age and body weight are important factors in IDWG and IDWG\%. Being young is associated with higher IDWG and its percentage. Our findings highlight the importance of personalized advice on fluid and sodium restriction.

\section{Additional Information \\ Disclosures}

Human subjects: Consent was obtained or waived by all participants in this study. Research Ethics Committee of the Zanjan University of Medical Science issued approval 08/90-327-02. Animal subjects: All authors have confirmed that this study did not involve animal subjects or tissue. Conflicts of interest: In compliance with the ICMJE uniform disclosure form, all authors declare the following: Payment/services info: All authors have declared that no financial support was received from any organization for the submitted work. Financial relationships: All authors have declared that they have no financial relationships at present or within the previous three years with any organizations that might have an interest in the submitted work. Other relationships: All authors have declared that there are no other relationships or activities that could appear to have influenced the submitted work.

\section{References}

1. Di Lullo L, Gorini A, Russo D, Santoboni A, Ronco C: Left ventricular hypertrophy in chronic kidney disease patients: from pathophysiology to treatment. Cardiorenal Med. 2015, 5:254-266. 10.1159/000435838

2. Segall L, Nistor I, Covic A: Heart failure in patients with chronic kidney disease: a systematic integrative review. Biomed Res Int. 2014, 2014:937398. 10.1155/2014/937398

3. López-Gómez JM, Villaverde M, Jofre R, Rodriguez-Benítez P, Pérez-García R: Interdialytic weight gain as a marker of blood pressure, nutrition, and survival in hemodialysis patients. Kidney Int. 2005, 67:S63-68. 10.1111/j.1523-1755.2005.09314.x

4. Flythe JE, Curhan GC, Brunelli SM: Disentangling the ultrafiltration rate-mortality association: the respective roles of session length and weight gain. Clin J Am Soc Nephrol. 2013, 8:1151-1161. 10.2215/CJN.09460912

5. Sherman RA, Cody RP, Rogers ME, Solanchick JC: Interdialytic weight gain and nutritional parameters in chronic hemodialysis patients. Am J Kidney Dis. 1995, 25:579-583. 10.1016/0272-6386(95)90126-4

6. Testa A, Beaud JM: The other side of the coin: interdialytic weight gain as an index of good nutrition . Am J Kidney Dis. 1998, 31:830-834. 10.1016/s0272-6386(98)70052-6

7. Stefánsson BV, Brunelli SM, Cabrera C, et al.: Intradialytic hypotension and risk of cardiovascular disease . Clin J Am Soc Nephrol. 2014, 9:2124-2132. 10.2215/CJN.02680314

8. Ifudu O, Uribarri J, Rajwani I, Vlacich V, Reydel K, Delosreyes G, Friedman EA: Relation between interdialytic weight gain, body weight and nutrition in hemodialysis patients. Am J Nephrol. 2002, 22:363368. $10.1159 / 000065228$

9. Sezer S, Nurhan Özdemir F, Arat Z, Perim Ö, Turan M, Haberal M: The association of interdialytic weight gain with nutritional parameters and mortality risk in hemodialysis patients. Ren Fail. 2002, 24:37-48. 10.1081/jdi-120002659

10. Bossola M, Pepe G, Vulpio C: The frustrating attempt to limit the interdialytic weight gain in patients on chronic hemodialysis: new insights into an old problem. J Ren Nutr. 2018, 28:293-301. 10.1053/j.jrn.2018.01.015

11. Santos SF, Peixoto AJ: Revisiting the dialysate sodium prescription as a tool for better blood pressure and interdialytic weight gain management in hemodialysis patients. Clin J Am Soc Nephrol. 2008, 3:522-530. 10.2215/CJN.03360807

12. de Araújo IC, Kamimura MA, Draibe SA, et al.: Nutritional parameters and mortality in incident hemodialysis patients. J Ren Nutr. 2006, 16:27-35. 10.1053/j.jrn.2005.10.003

13. Herselman M, Moosa MR, Kotze TJ, Kritzinger M, Wuister S, Mostert D: Protein-energy malnutrition as a risk factor for increased morbidity in long-term hemodialysis patients. J Ren Nutr. 2000, 10:7-15. 10.1016/s1051-2276(00)90017-7

14. Kalantar-Zadeh K, Supasyndh O, Lehn RS, McAllister CJ, Kopple JD: Normalized protein nitrogen appearance is correlated with hospitalization and mortality in hemodialysis patients with Kt/V greater than 1.20. J Ren Nutr. 2003, 13:15-25. 10.1053/jren.2003.50005

15. Iorember FM: Malnutrition in chronic kidney disease . Front Pediatr. 2018, 6:161. 10.3389/fped.2018.00161

16. Rahman M, Fu P, Sehgal AR, Smith MC: Interdialytic weight gain, compliance with dialysis regimen, and age are independent predictors of blood pressure in hemodialysis patients. Am J Kidney Dis. 2000, 35:257-265. 10.1016/s0272-6386(00)70335-0

17. Laville M, Fouque D: Nutritional aspects in hemodialysis. Kidney Int. 2000, 58:S133-139. 10.1046/j.15231755.2000.07617.x

18. Ipema KJ, Kuipers J, Westerhuis R, Gaillard CA, van der Schans CP, Krijnen WP, Franssen CF: Causes and consequences of interdialytic weight gain. Kidney Blood Press Res. 2016, 41:710-720. 10.1159/000450560

19. Hecking M, Karaboyas A, Saran R, et al.: Dialysate sodium concentration and the association with interdialytic weight gain, hospitalization, and mortality. Clin J Am Soc Nephrol. 2012, 7:92-100. 


\section{Cureus}

$10.2215 /$ CJN.05440611 